\title{
SEISMIC POUNDING BETWEEN ADJACENT RC BUILDINGS WITH AND WITHOUT BASE ISOLATION SYSTEM
}

\author{
Raghunandan M H ${ }^{1}$, Suma Devi ${ }^{2}$ \\ ${ }^{1}$ Post Graduate student, Structural Engineering, SVCE Bangalore, Karnataka, India \\ ${ }^{2}$ Assistant Professor, Civil Engineering, SVCE Bangalore, Karnataka, India
}

\begin{abstract}
Among the possible structural damages during an earthquake, the seismic induced pounding also has been one of the commonly observed phenomena. This is because the separation gap between many adjacent buildings is inadequate to accommodate the relative motions, so buildings vibrate out of phase and collides. Despite the fact that the seismic pounding between nearby structures is considered in the codal procurements, the act of development is still an issue in numerous metropolitan zones where the structures are built with no adequate partition separation which brings about their pounding. In this study E-Tabs nonlinear software is used for simulation of adjacent multi-storeyed RC frame buildings of $G+14$ and $G+9$ storey, the provisions that may reduce the effects of pounding like the separation distance, addition of shear walls, lateral bracings and variation in storey height of the buildings have been considered for analysis. And the responses like storey-displacement and pounding force by considering both fixed base and base-isolated conditions are arrived.
\end{abstract}

Keywords: Seismic pounding, RC frame building, Separation distance, Gap elements, Storey-displacement Pounding force, Fixed-base, Base isolation.

\section{INTRODUCTION}

This seismic pounding causes severe damage to the structures under earthquakes, owing to their different dynamic characteristics. During earthquake the building structures vibrate in out of phase and the separation is not sufficient to accommodate their relative motions. But this collision can be avoided by providing safe separation distance also called as seismic gap; however sometimes getting the required safe separations is not possible in metropolitan areas, due to increase in land values and population [1]. So the buildings may have been constructed very close to each other and the existing space between those buildings may not be enough for avoiding the pounding. Although the seismic pounding between fixedbase buildings had been studied exclusively for more than decades, the seismic pounding between base-isolated buildings had not drawn much attention. Also the past earthquakes showed us the detrimental effects caused by seismic pounding on performance of the conventional buildings with fixed base, which ranges from the local damage to severe structural failure. But, the consequences of earthquake induced pounding on the seismically isolated buildings may be more substantial and those required being assessed [6]. Thus there is a need for studying the effects of isolated buildings on pounding as well as of pounding on base isolated buildings. If the building separation is found to be inefficient for avoiding the pounding, then there should be some suitable methods for preventing the structural pounding between adjacent buildings. This can be achieved by including superior design procedures for making the buildings stable against strong ground motions. Since distance between the buildings cannot be increased in case of existing buildings and new buildings due to constructional difficulties, so we have to arrive at an alternate solution for this problem. This is done by enhancing the lateral stiffness of one building or both the buildings by providing the shear walls or lateral bracings in a way that it will reduce the displacement and can be accommodated between the available separation distances. On the other hand if the strength and stiffness of a frame is not adequate then the frame system may be strengthened by including load-bearing walls, lateral bracings or shear walls. Bracings and shear walls are also helpful in preventing the failure of non-structural components by reducing the deflection. Shear walls or lateral bracings located at suitable positions in a building can significantly resist lateral loads due to earthquake or wind. These may be of RCC, steel or composite etc. Both lateral bracings and shear walls are used as effective mitigation strategies. The location of shear walls in building are selected in such a way, that the distance between center of mass and center of rigidity is kept as low as possible in order to reduce the additional forces developed due to torsion.

\subsection{Base Isolation System}

The base isolation technology is one of the most innovative approaches for anti-seismic designing of the structures that has been widely used from last few years. The term base isolation in which the word isolation means state of being separated and the word base is a part that supports beneath or serves as a foundation for super structure. So we can understand this concept as the structures which are separated from their foundation. In other sense, the term seismic isolation is more accurate in which the structure is being 
separated from the ill effects of seismic motion [5]. The new design philosophy on anti-seismic design criteria emerged aiming for reducing the seismic damages by providing isolators at the base of the structures. However, in seismically isolated structures the peak base displacement increases significantly during earthquake and the structure can impact on adjacent structures like buildings, retaining walls, ramps, boundary walls etc. In case of longer buildings the expansion gaps are provided invariably in order to accommodate the displacements due to variation in temperature. For such buildings there are likely chances of impact at their expansion gap when these two buildings vibrate out of phase.

\subsection{Lead Rubber Bearing (LRB)}

This is a type of elastomeric bearing having higher value of damping which is obtained by arranging a core of lead in the centre of the bearing, where the energy absorption is obtained by yielding of the lead, which remains hooped by the thin layers of low damping natural rubber and alternate layers of steel plates.

\subsection{Gap Elements}

Gap element is an element which connects two adjacent nodes to model the contact and is defined as a link element in ETABS software, this link element is activated only when the structures come closer and deactivate when they go far away and a collision force will be generated when they come closer. So it is a compression-only element required to assess the pounding force and to simulate the effect of pounding.

\subsection{Analysis Methods}

Equivalent Static Analysis: Seismic analysis of most structures is still carried out on the assumption that the lateral force is equivalent to the actual loading. This method of finding design lateral forces is also known as the static method or the equivalent lateral force method or the seismic coefficient method.

Response Spectrum Analysis: This method is also known as modal method or mode superposition method. In the response spectrum method, the peak response of a structure during an earthquake is obtained directly from the earthquake response spectrum. The responses of different modes are combined to provide an estimate of total response of the structure using modal combination methods such as complete quadratic combinations (CQC), square root of sum of squares (SRSS), or absolute sum (ABS) method.

Time History Analysis: A time history analysis overcomes all the disadvantages of a modal response spectrum analysis. This method requires greater computational efforts for calculating the response at discrete times. One interesting advantage of such a procedure is that the relative signs of response quantities are preserved in the response histories. This is important when interaction effects are considered among stress resultants [7].

\section{METHODOLOGY}

The multi-storeyed RC frame buildings are modelled in ETABS nonlinear software. The two buildings consist of $\mathrm{G}+14$ and $\mathrm{G}+9$ special moment resisting frame considered to be situated in seismic zone $\mathrm{V}$ having medium soil and intended for residential use and separated by an initial gap of $50 \mathrm{~mm}$. Both buildings are modelled in E-tabs software, are subjected to gravity and dynamic loads are analysed by equivalent static analysis and response spectrum analysis methods. And to observe pounding, time history analysis is carried out taking data of Elcentro.

Pounding is considered at slab level of tenth storey, for observing positive displacement of $\mathrm{G}+14$ storey building and negative displacement of $\mathrm{G}+9$ storey building. Beams and column members have been defined as frame elements and the columns have been restrained in all six degrees of freedom at the base. Slabs are defined as area elements having the properties of membrane elements and have been modelled as rigid diaphragms. Also concrete bracings and shear walls are defined as frame elements and shell area elements respectively.

Building 1 and 2 having grade of concrete for beam, slab, brace and shear wall is M20 and for column is M25, with unit weight of concrete being $25 \mathrm{kN} / \mathrm{m}^{3}$, Column size for building 1 and 2 is taken as $0.6 \times 1 \mathrm{~m}$, while the beam size is $0.35 \times 0.6 \mathrm{~m}$ and bracing size of $0.2 \times 0.2 \mathrm{~m}$. The slab thickness of $130 \mathrm{~mm}$ and shear wall thickness of $200 \mathrm{~mm}$ are taken. Building 1 having $\mathrm{G}+14$ storeys with 5 bays in $\mathrm{X}$ and $\mathrm{Y}$ directions, width of bay in $\mathrm{X}$ direction is $4.5 \mathrm{~m}$ and in $\mathrm{Y}$ direction is $4.5 \mathrm{~m}$. Building 2 having G+9 storeys with 4 bays in $\mathrm{X}, 5$ bays in $\mathrm{Y}$ direction, and width of bay in $\mathrm{X}$ direction is $4 \mathrm{~m}$ and in $\mathrm{Y}$ direction is $5 \mathrm{~m}$. 


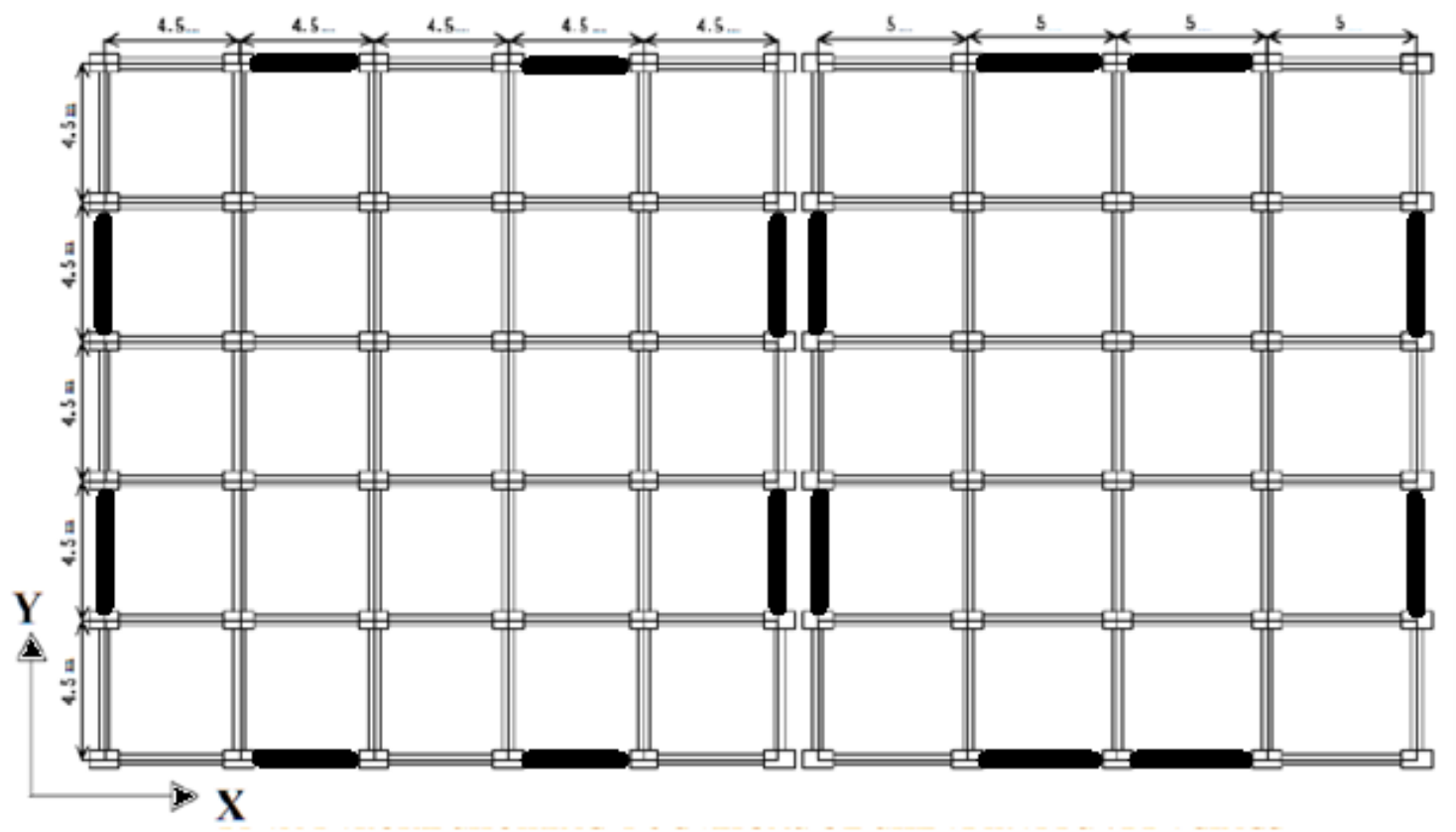

Fig -1: Plan layout showing the locations of shear walls and $\mathrm{X}$ bracings
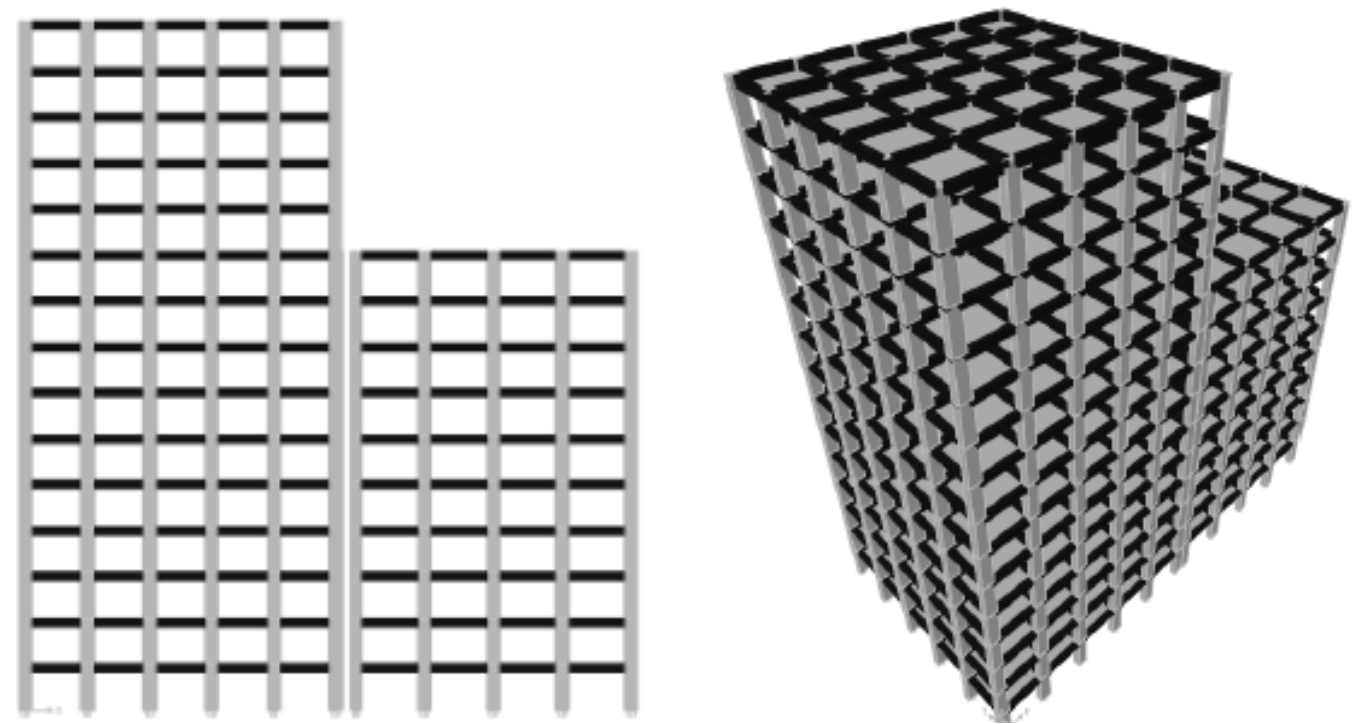

Fig -2: Elevation and 3D view of bare frame buildings

\section{RESULTS AND DISCUSSIONS}

Most of the past studies which were done on adjacent buildings with fixed base and mitigation strategies for the same to reduce the pounding effects, but in case of the buildings with base isolators will definitely show some changes in their behaviour when compared with the conventional fixed base buildings during the earthquake.

For this reason in our study we considered the effect of base isolator during the seismic induced pounding, so in our study the first set of models will be adjacent buildings with both having fixed base as well as in the next set of models we considered adjacent buildings where the taller one with fixed base and the shorter building with isolated base.

\subsection{Storey Displacement}

The storey displacement at each level with respect to ground for various building model are obtained from the equivalent static analysis, response spectrum analysis and time history analysis methods and the required seismic gap for maximum relative displacement between adjacent buildings is shown in table-1 based on SRSS and ABS methods with are also presented in chart- 1 and chart- 2 below. 
Table -1: Calculation of required seismic gap for various analysed models by SRSS and ABS methods Calculation of required gap by SRSS and ABS methods

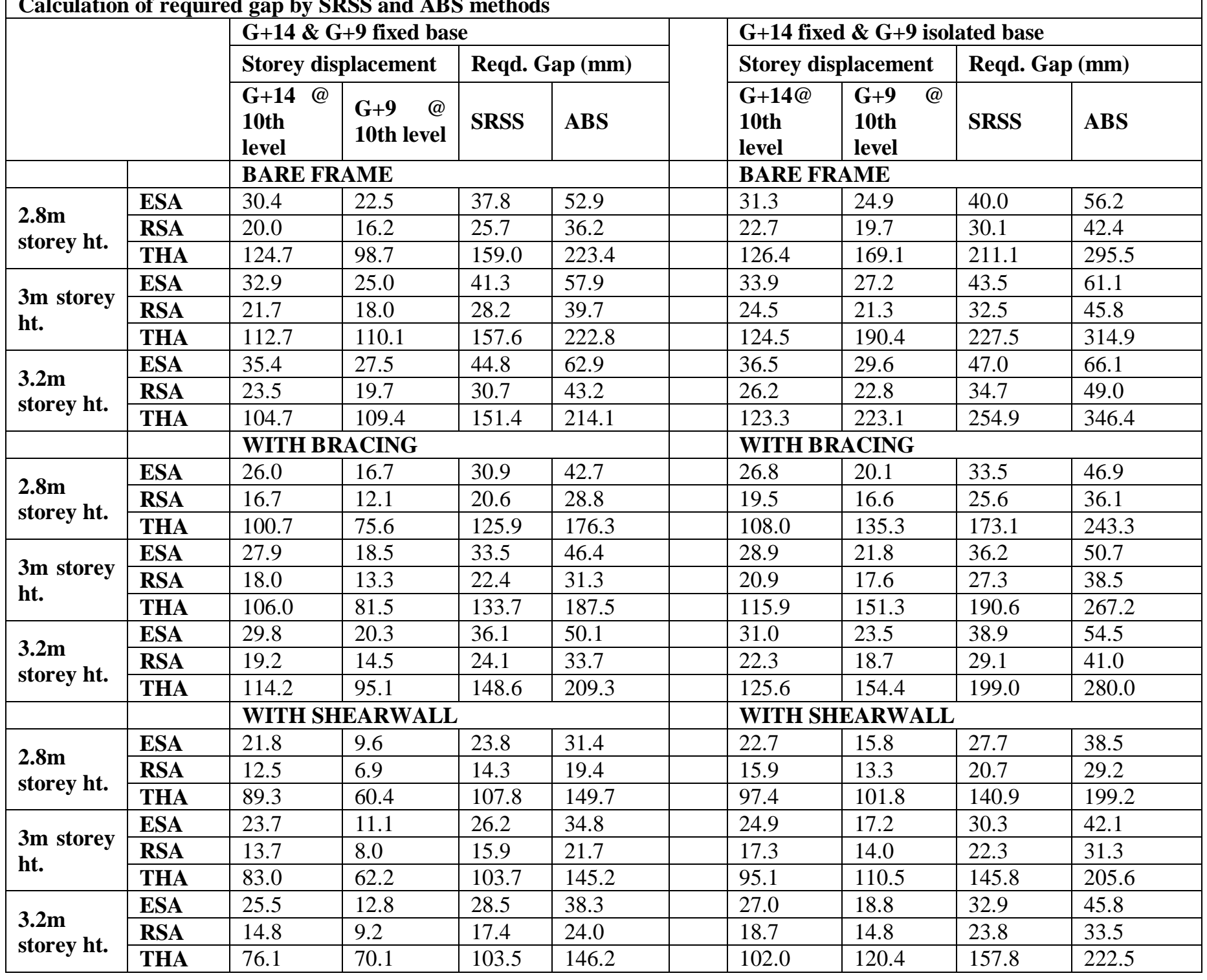

According to SRSS and ABS methods when fixed base adjacent buildings are compared, the gap required between $\mathrm{G}+14$ fixed base adjacent to $\mathrm{G}+9$ isolated base buildings increases by $5-15 \%, 15-25 \%$ and $25-40 \%$ with ESA, RSA and THA respectively. Time history analysis is showing huge displacement values, because of huge acceleration. The maximum relative displacement decreases upto $15-25 \%$ by using bracings and $35-45 \%$ by shearwalls, where shearwalls reduces storey displacement much higher than the bracings. As the relative displacement decreases, the required seismic gap can be minimized.

Therefore we can say that the seismic gap required between any adjacent buildings can be optimized by using lateral load resisting frame systems with proper placement of bracings and shear walls. 


\section{ESA/SRSS method}

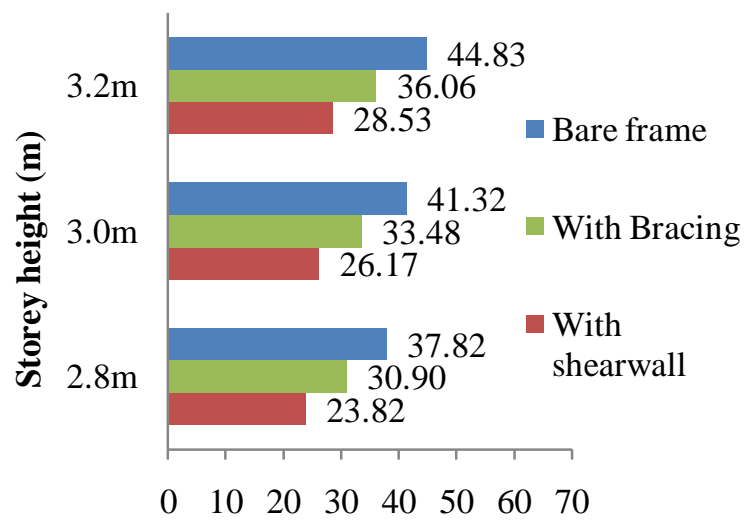

Required Seismic Gap (mm)

\section{RSA/SRSS method}

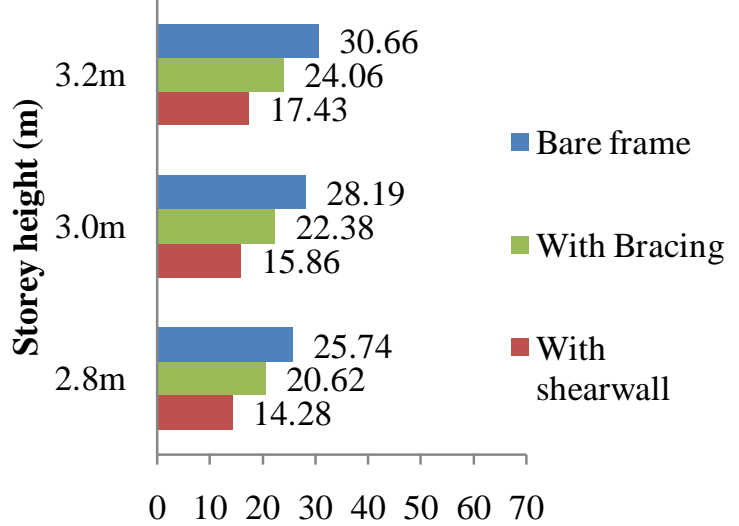

Required Seismic Gap (mm)

\section{THA/SRSS method}

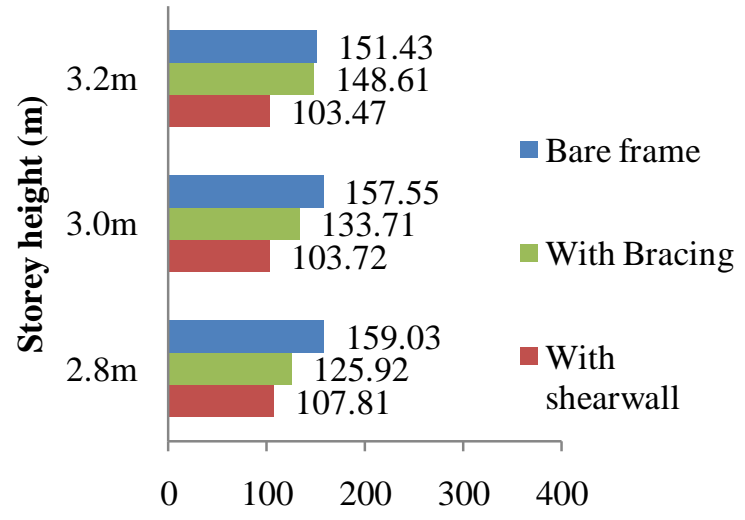

Required Seismic Gap (mm)

Chart -1: Comparison of required seismic gap b/w G+14 and $\mathrm{G}+9$ fixed base adj. buildings by SRSS method

\section{ESA/SRSS method}

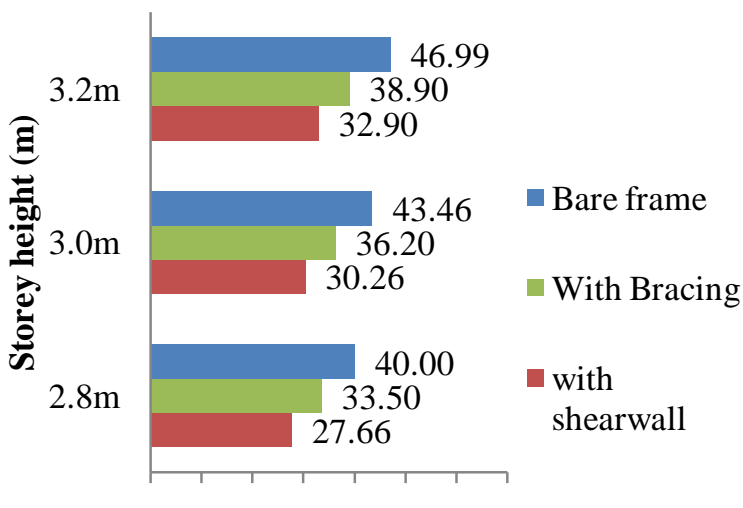

$0 \quad 10203040506070$

Required Seismic Gap (mm)

\section{RSA/SRSS method}

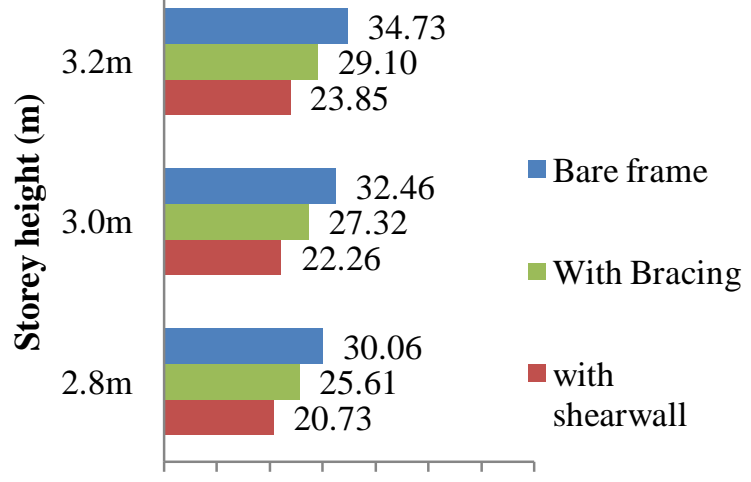

$0 \quad 10 \quad 20 \quad 30 \quad 40 \quad 50 \quad 60 \quad 70$

Required Seismic Gap (mm)

THA/SRSS method

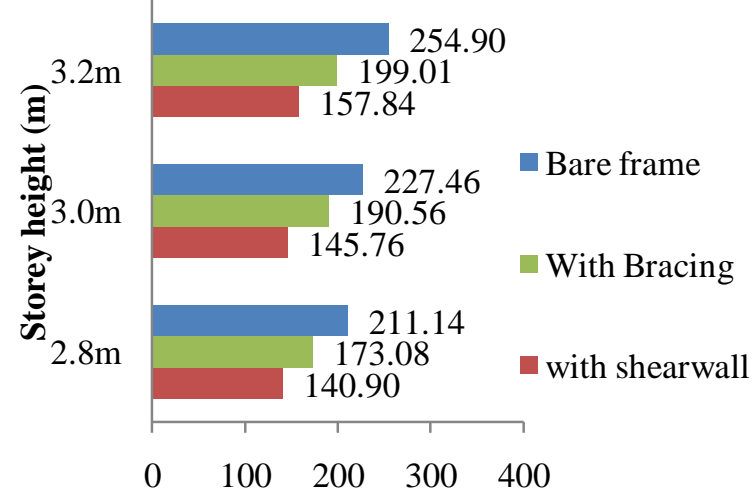

Required Seismic Gap (mm)

Chart -2: Comparison of required seismic gap b/w G+14 fixed and $\mathrm{G}+9$ isolated base adj. buildings by SRSS method. 


\subsection{Pounding Force}

Pounding force is the force exerted by a buiding to its adjacent building when they strike each other during pounding phenomena. This pounding force can be minimised by increasing the seperation gap between

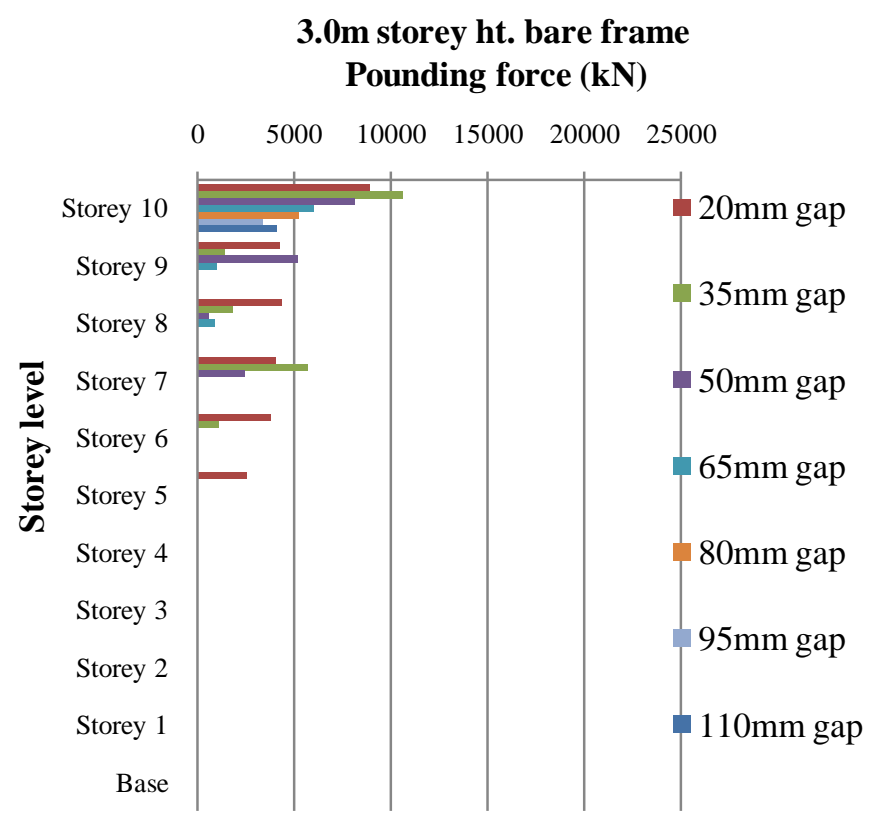

3.0m storey ht. with bracings

Pounding force $(\mathrm{kN})$

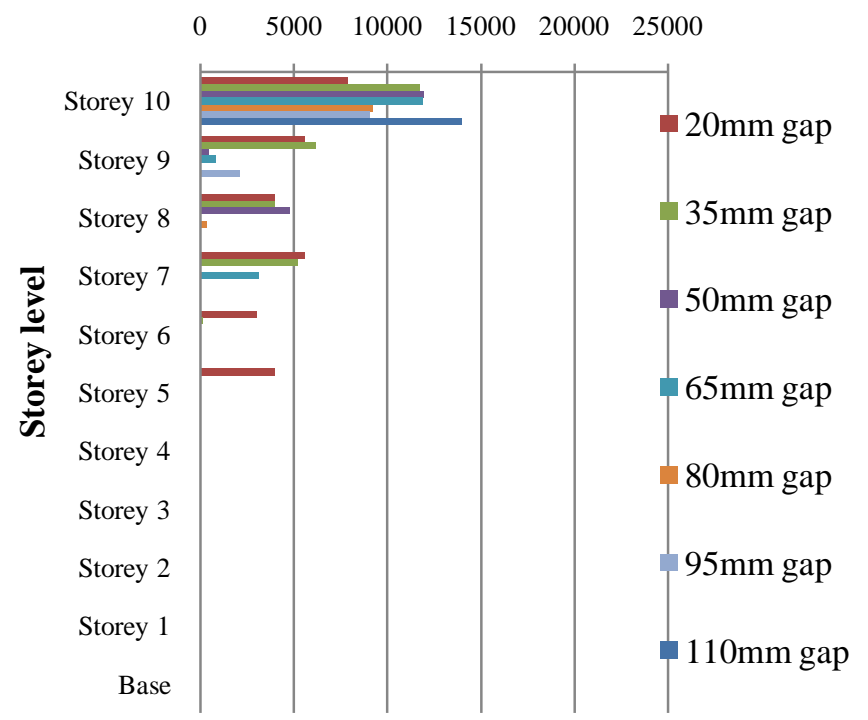

adjacent buildings. The storey pounding force at each storey level and at base level is obtained by placing non linear link elements at each level between two adjacent buildings and analysed based on Elcentro, 1940 acceleration data for various building models are shown below.

\section{0m storey ht. bare frame Pounding force $(\mathrm{kN})$}

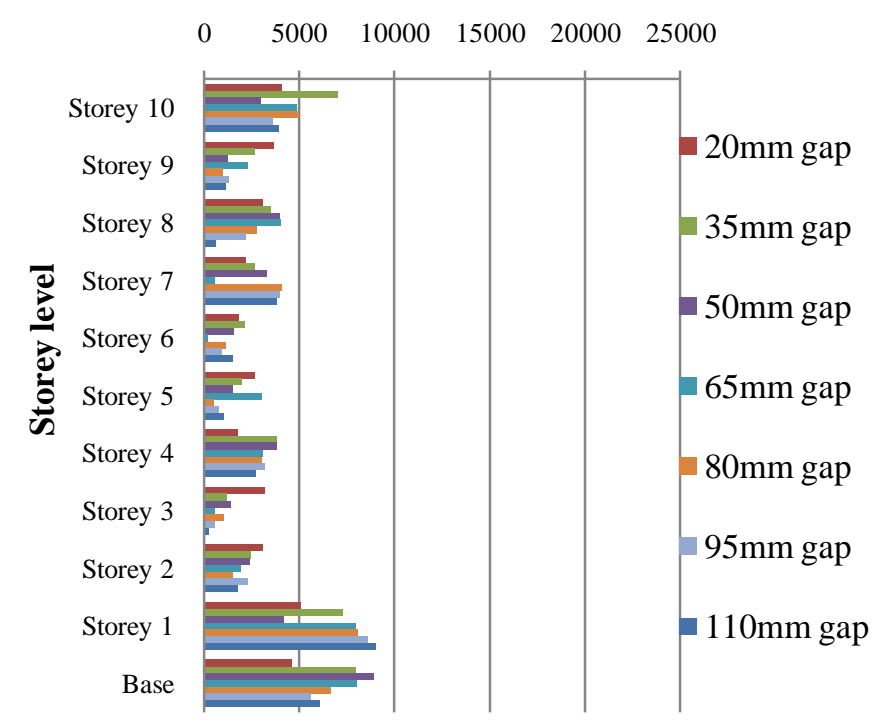

\section{0m storey ht. with bracings}

Pounding force $(\mathrm{kN})$

$\begin{array}{llllll}0 & 5000 & 10000 & 15000 & 20000 & 25000\end{array}$

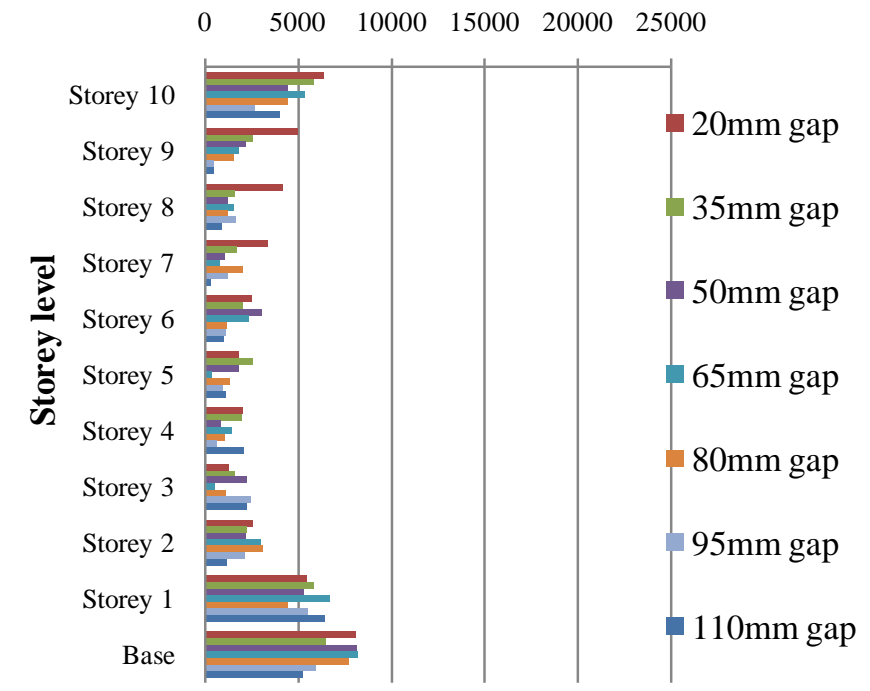




\section{0m storey ht. with shearwalls \\ Pounding force $(\mathrm{kN})$}

$\begin{array}{llllll}0 & 5000 & 10000 & 15000 & 20000 & 25000\end{array}$

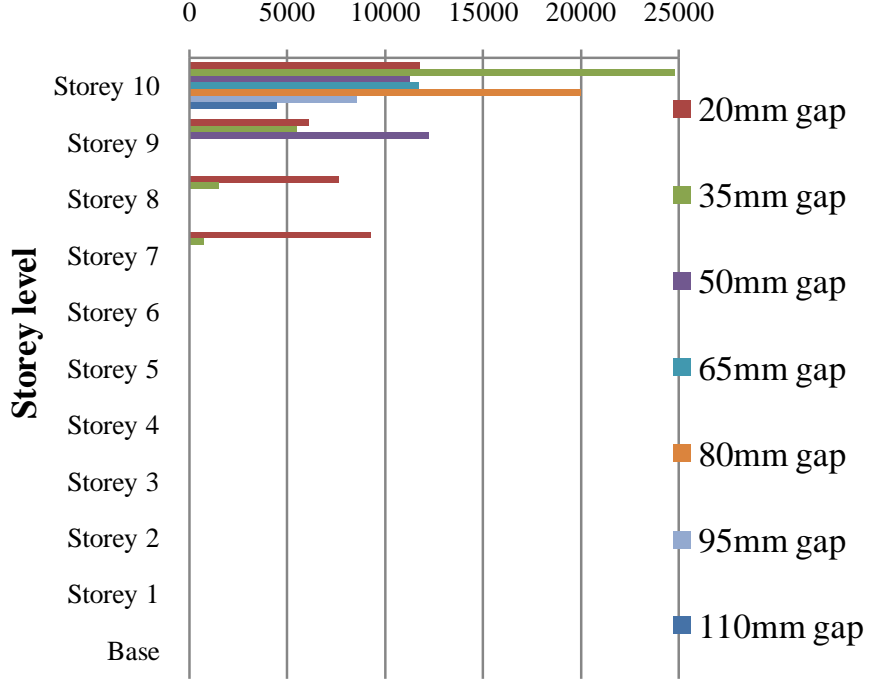

Chart -3: Storey pounding force b/w G+14 and G+9 fixed base adj. buildings for various seismic gaps.

\section{0m storey ht. with shearwalls}

Pounding force $(\mathrm{kN})$

$\begin{array}{llllll}0 & 5000 & 10000 & 15000 & 20000 & 25000\end{array}$

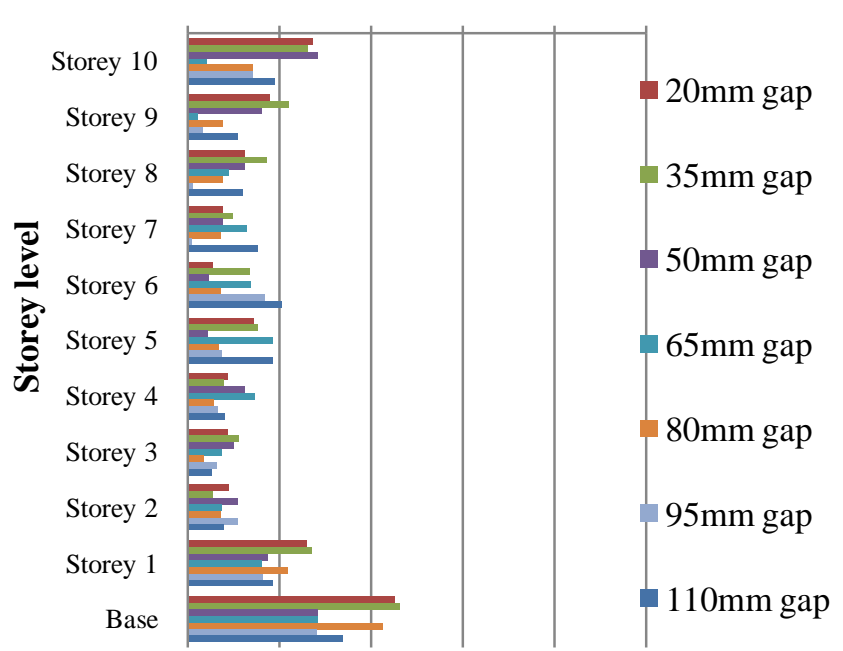

Chart -4: Storey pounding force $\mathrm{b} / \mathrm{w} \mathrm{G}+14$ fixed and $\mathrm{G}+9$ isolated base adj. buildings for various seismic gaps.

Table -2: Comparison of maximum pounding force with variation of storey height and frame system

\begin{tabular}{|l|l|l|l|l|l|l|}
\hline \multicolumn{5}{|l|}{ Comparison of maximum Pounding force $(\mathbf{k N})$} \\
\hline & G+14 and G+9 fixed base adj. buildings & \multicolumn{2}{l|}{ G+14 fixed and G+9 isolated base adj. building } \\
\hline Storey ht. & Bare frame & With Bracing & With Shear wall & Bare frame & With Bracing & With Shear wall \\
\hline $2.8 \mathrm{~m}$ & 12241.1 & 12929.2 & 22592.8 & 7856.24 & 8512.33 & 10742.4 \\
\hline $3.0 \mathrm{~m}$ & 10620.9 & 13959.1 & 24737 & 8998.04 & 8182.37 & 11575.3 \\
\hline $3.2 \mathrm{~m}$ & 17590.6 & 14361.3 & 12297.4 & 10740.7 & 8810.81 & 11688.2 \\
\hline
\end{tabular}

Max Pounding force $b / w$ fixed base buildings

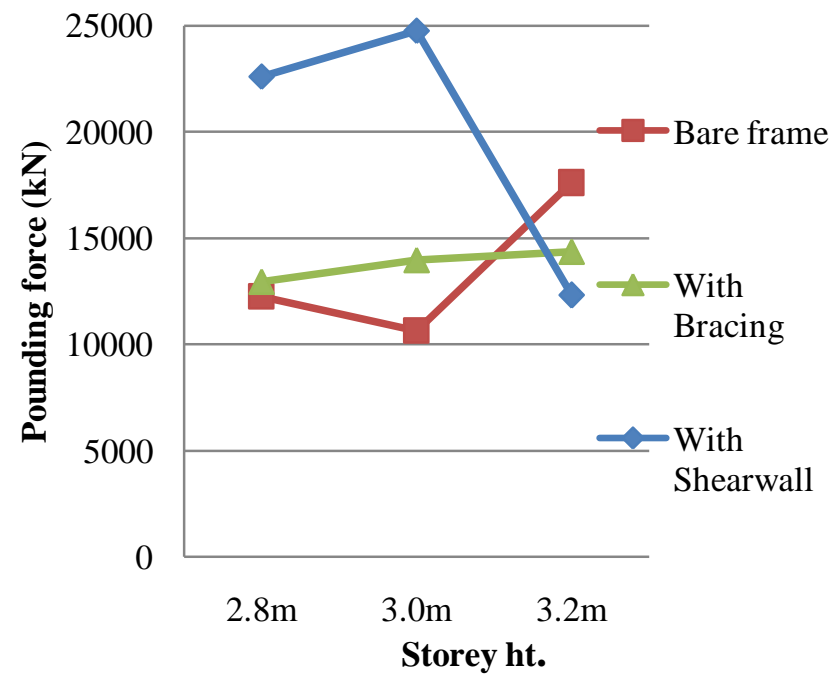

Chart -5: Comparison of maximum pounding force $b / w$ G+14 and G+9 fixed base adj. buildings with variation of storey height and frame system.

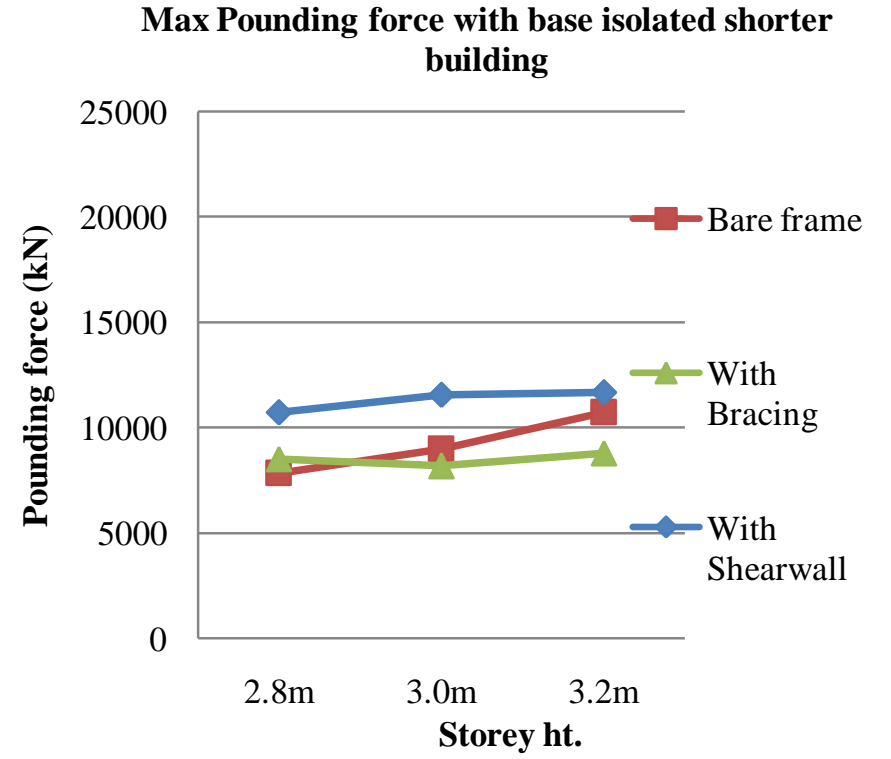

Chart -6: Comparison of maximum pounding force $b / w$

G+14 fixed and G+9 isolated base adj. buildings with variation of storey height and frame system. 
From the above chart 3 and 4 we can observe that incase of $\mathrm{G}+14$ and $\mathrm{G}+9$ fixed base adjacent buildings pounding effect is experienced only at few of the top storeys and the force non linearly varies and diminishes with increase in seperation distance. But in case of $\mathrm{G}+14$ fixed adjacent to $\mathrm{G}+9$ isolated-base building the effect can be seen through the height of the buildings. Also we see the maximum pounding force at the top for $\mathrm{G}+14$ and $\mathrm{G}+9$ fixed base adjacent buildings, where as for $\mathrm{G}+14$ fixed adjacent to $\mathrm{G}+9$ isolated base building the maximum pounding force is at the base level.

From table-2, chart 5 and 6 we found that both incase of the $\mathrm{G}+14$ and $\mathrm{G}+9$ fixed base adjacent buildings and $\mathrm{G}+14$ fixed adjacent to $\mathrm{G}+9$ isolated base building the presence of shearwalls shows maximum pounding force when compared with bare framed or withbracings. And the bracings in buildings helps in maintaining the linearity of pounding force with variation of storey height. Therefore we can say that the pounding effect between any adjacent buildings can be optimized by use of bracings and increase in seperation gap between them.

\section{CONCLUSION}

\subsection{Storey Displacement}

- Storey displacement value increases with increase in the storey height or building height. Use of isolators induces displacement even at the base level in addition to increase in top displacement when compared to fixed base building.

- $\quad$ The gap required between fixed base taller adjacent to isolated base shorter buildings increases by $5-15 \%, 15-$ $25 \%$ and $25-40 \%$ with ESA, RSA and THA respectively when compared with fixed base adjacent buildings.

- The maximum relative displacement decreases by using bracings and shearwalls. As relative displacement decreases, the required seismic gap can be minimized.

\subsection{Pounding Force}

- In fixed base adjacent buildings pounding effects only at few of the top storeys, but in case of fixed base taller adjacent to isolated base shorter building the pounding effects through the height of the buildings.

- $\quad$ Also the maximum pounding force occurs at the top for fixed base adjacent buildings, where as for fixed base taller adjacent to isolated base shorter building the maximum pounding force will be at the base level.

- $\quad$ The presence of shearwalls shows maximum pounding force when compared with bare framed or with bracings. Where as bracings in buildings helps in maintaining the linearity in pounding force with variation of storey height.

- Finally the pounding effect between any adjacent buildings can be optimized by use of bracings and increase in seperation gap between them.

\section{REFERENCES}

[1] Ravindranatha, Tauseef M Honnyal, Shivananda S.M, H Suresh, " A Study of Seismic Pounding between Adjacent Buildings" International Journal of Research in Engineering and Technology, vol-03, special issue-03, May-2014, pp.795-799.

[2] Khaja Afroz Jamal, H.S.Vidyadhara, "Seismic Pounding of Multi-storeyed Buildings", International Journal of Research in Engineering and Technology, IC-RICE conference issue, Nov-2013, pp.12-17.

[3] Shahzad Jamil Sardar, Umesh. N. Karadi, "Effect of Change in Shear Wall Location on Storey Drift of Multi-storey Building Subjected to Lateral Loads", International Journal of Innovative Research in Science, Engineering and Technology, vol-2, issue-9, Sept-2013, pp.4241-4249.

[4] Shirule Pravin Ashok, Niraj Mehta, Rahul Wagh , Mayur Padhiyar ,Ankesh Samare \& Yogesh Patil, "Response Spectrum Analysis of Multi Storeyed Base-Isolated Building", International Journal of Civil, Structural, Environmental and Infrastructure Engineering Research and Development, vol-2, issue 3, Sept 2012, pp.66-75.

[5] A. B. M. Saiful Islam, Mohammed Jameel and Mohd Zamin Jumaat, "Seismic Isolation in Buildings to be a Practical Reality: Behavior of Structure and Installation Technique", Journal of Engineering and Technology Research, vol-3, issue-4, April 2011, pp.99-117.

[6] Panayiotis C. Polycarpou, Petros Komodromos, "Earthquake-Induced Poundings of a Seismically Isolated Building with Adjacent Structures", Engineering Structures, vol-32, 2010, pp.1937-1951.

[7] S.K. Duggal, "Earthquake Resistant Design of Structures”, Oxford University Press, 2007.

[8] Susendar Muthukumar and Reginald DesRoches, "A Hertz contact model with non-linear damping for pounding simulation", Earthquake Engineering and Structural Dynamics, vol-35, Feb-2006, pp.811-828.

[9] C. V. R. Murty, "Earthquake Tips - Learning Earthquake Design and Construction", Department of Civil Engineering, Indian Institute of Technology Kanpur, Sept-2005.

[10] CSI Analysis Reference Manual for E-tabs, Computers and Structures, Inc, Berkeley, California, USA, 2005.

[11] IS 1893 (Part-1):2002, "Indian Standard Criteria for Earthquake Resistant Design of Structures, General Provisions and Buildings, (Fifth Revision)", Bureau of Indian Standards, New Delhi.

[12] FEMA-273:1997, "NEHRP guidelines for the seismic rehabilitation of buildings", Washington DC. 


\section{BIOGRAPHIES}

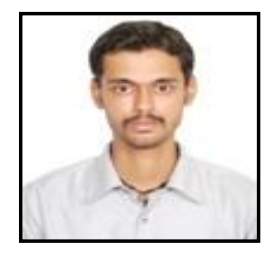

Raghunandan M H PG student in Structural Engineering at SVCE, Bangalore and obtained his B.E. in Civil Engineering from SJBIT, Bangalore.

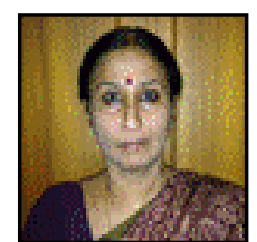

Suma Devi obtained her M.E. in Earthquake Engineering from Bangalore University and B.Tech in Civil Engineering from Calicut University. She has 11 years industrial experience in residential, commercial, infrastructure projects \& 15 years of academic experience 